Article

\title{
Study on Flow Characteristics of Cryogenic Hybrid Journal Bearings
}

\author{
Mamoru Oike ${ }^{1)^{*}}$, Masataka Kikuchi ${ }^{2)}$, Satoshi Takada ${ }^{2)}$, Takayuki Sudo ${ }^{2)}$ and Tomoyuki Takano ${ }^{3)}$ \\ ${ }^{1)}$ Department of Mechanical Engineering, Ishinomaki Senshu University \\ 1 Shinmito, Minamisakai, Ishinomaki, Miyagi 986-8580, Japan \\ ${ }^{2)}$ Kakuda Space Center, Japan Aerospace Exploration Agency \\ 1 Koganezawa, Kimigaya, Kakuda, Miyagi 981-1525, Japan \\ ${ }^{3)}$ Japan Aerospace Technology \\ 1 Koganezawa, Kimigaya, Kakuda, Miyagi 981-1525, Japan \\ *Corresponding author: oike@isenshu-u.ac.jp
}

( Manuscript received 16 November 2015; accepted 01 January 2016; published 15 September 2016 )

( Presented at the International Tribology Conference Tokyo 2015, 16-20 September, 2015)

\begin{abstract}
In the present study, a flow visualization experiment in the clearance between a clear floating-ring and a rotating journal was carried out in order to clarify the effect of the sweepback angle $\left(\theta_{s}\right)$ of the leading edge of the recess on the flow characteristics. Four types of the floating-rings with different recess geometries, i. e., the Young Leaf Mark, the square and the non-recessed geometries, were operated at a rotational speed of up to 45,000 rpm using liquid nitrogen as the working fluid to observe the interaction between source flow from the recess and rotating flow induced by the journal rotation in the clearance. The cavitation cloud inside the clearance was induced by viscous frictional heating and the pressure drop. The influence of the $\theta_{s}$ value on the flow characteristics was investigated by comparing flow coefficient $\left(C_{f}\right)$ and the cavitation cloud area ratio (Ac) obtained from the visual image. Based on the experimental results, the dependence of the flow characteristics on the rotational speed was confirmed to be affected by the sweepback angle of the leading edge of the recess.
\end{abstract}

Keywords: journal bearing, cryogenic turbopump, flow visualization, recess sweepback angle, cavitating flow, liquid nitrogen

\section{Introduction}

The lifetime of a rocket engine depends mainly on the durability of bearings and seals in a cryogenic turbopump. Almost all cryogenic turbopumps of rocket engines have a rotor system supported by self-lubricating ball bearings operated in liquid hydrogen or liquid oxygen. Since a differential slip and Hertz stress act in the rolling contact area between a ball and a raceway, it is difficult to avoid the lifetime shortening wear of material inside the contact area. Moreover, the polytetrafluoroethylene (PTFE) solid lubricant film on the contact area has a limitation of the $S V$ value, which is the value of Hertzian stress $(S)$ times the differential slip speed $(V)$, to maintain a good lubricating condition in the cryogenic fluid [1]. Therefore, the rotational speed of the cryogenic turbopump must be restricted to avoid critical damage such as seizing. A hybrid journal bearing (HJB) is a fluid-film journal bearing with characteristics of both hydrostatic and hydrodynamic bearings. The main advantage of HJBs are small size, good load capacity, a quasi-unlimited life (no observed wear), and the use of process fluid for lubrication [2]. By replacement of the self-lubricating ball bearings in the cryogenic turbopumps by HJBs, a significantly higher lifetime can be obtained and the inherent limitation of the rotational speed of the turbopumps can be greatly extended in cryogenic rocket engines for future reusable launch vehicles (RLVs), where the lifetime of mechanical components is a critical issue. Although many experimental studies on HJBs have been carried out to develop high performance HJBs for cryogenic turbopumps [3-7], it has not yet been completely realized because there is little demand for development of a launch vehicle capable of being reused over hundred times. However, detailed reference data based on experimental results will be required to develop high performance cryogenic HJBs in the near future.

In a previous study [8], two types of hybrid journal bearings (HJBs) with different recess geometries, i.e., the Young Leaf Mark (YLM, Types Ca and D in Fig. 1) and the square (Type $\mathrm{Ba}$ ), were operated at a rotational speed of up to $67,000 \mathrm{rpm}$ using liquid nitrogen as the 

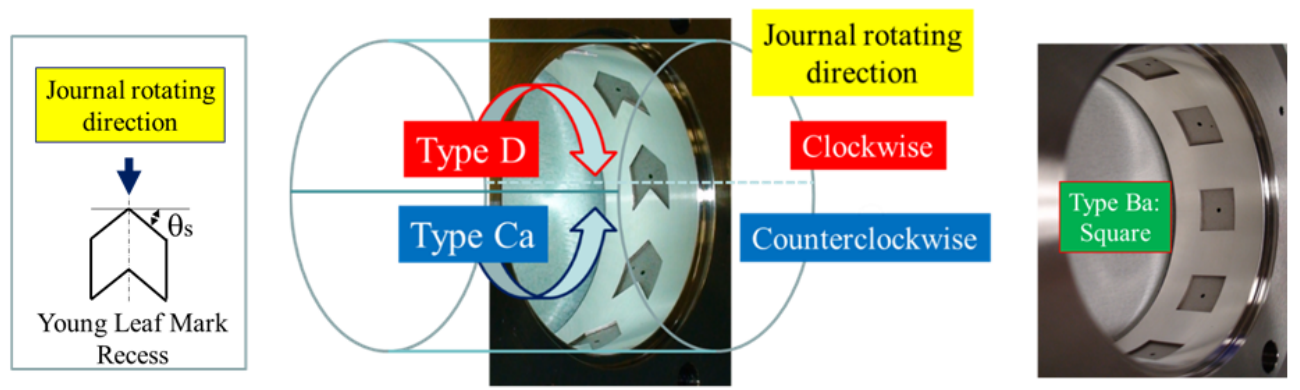

Fig. 1 Photos of test HJB inner surfaces with Young Leaf Mark recess (Journal rotating direction: counterclockwise for Type $\mathrm{Ca}$, clockwise for Type D) and square recess (Type Ba) [8]

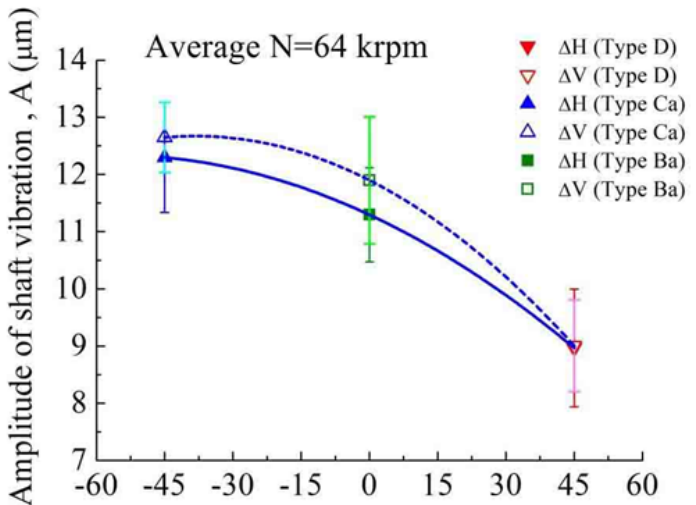

Sweepback angle of recess leading edge, $\theta_{\mathrm{s}}(\mathrm{deg})$

Fig. 2 Comparisons of the horizontal and vertical amplitudes $(\Delta H$ and $\Delta V)$ of the rotor vibration for Types $\mathrm{D}, \mathrm{Ca}$ and $\mathrm{Ba}$ [8]

working fluid in order to clarify the influences of the journal rotating direction on performance of the cryogenic HJBs. The dependence of the rotor vibration on the rotational speed was confirmed to be affected by the direction of journal rotation. As shown in Fig. 2, the test HJB with the positive sweepback angle $\left(\theta_{s}\right)$ of the recess leading edge showed the smallest rotor vibration in the high-rotational-speed operation where the hydrodynamic effect was predominant.

In the present study, a flow visualization experiment in the clearance between a clear floating-ring (CFR) and a rotating journal was carried out in order to clarify the effect of the $\theta_{s}$ value on the flow characteristics. Four types of CFR with different recess geometries, i. e., the YLM, the square and the non-recessed geometries, were operated at a rotational speed of up to $45,000 \mathrm{rpm}$ using liquid nitrogen $\left(\mathrm{LN}_{2}\right)$ to observe the interaction between a source flow from the recess and rotating flow induced by the journal rotation in the clearance. The influence of the $\theta_{s}$ value on the flow characteristics was investigated by comparing the flow coefficient $\left(C_{f}\right)$ and the cavitation cloud area ratio $(A c)$ obtained from the visual image.

\section{Experimental procedure}

\subsection{Clear floating-ring}

Flow visualization experiments were conducted to clarify the flow pattern of cryogenic fluid within the clearance between the CFR and the journal. Figure 3 is a photograph of the test CFR (Type D) section. The test CFR made of polycarbonate is a floating-ring which has four orifice-compensated recesses on the inner surface to simulate the interaction between a source flow from the recess and a rotating flow induced by the journal rotation in the clearance of the HJB, as shown in Fig. 3. Three types of the CFRs have different recess geometries, i. e., the Young Leaf Marks and the square, and another type is a simple floating-ring with no recess. The geometry parameters of the test CFRs including the

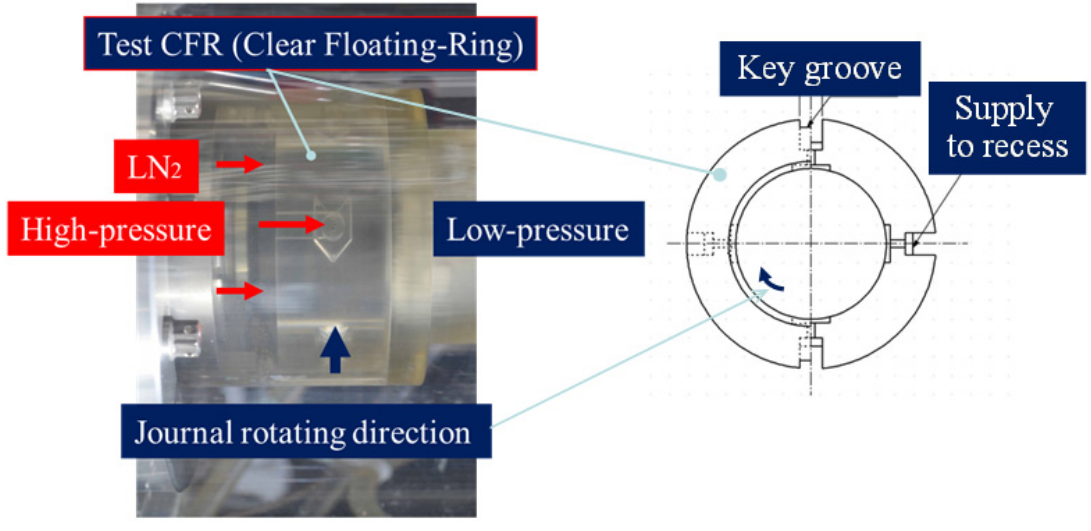

Fig. 3 Photograph of the test CFR (Type D) section 
Table 1 Geometry parameters of test CFR

\begin{tabular}{|l|c|c|c|c|}
\hline Type of CFR & Type B & Type C & Type D & Type FR \\
\hline Diameter of CFR, $d(\mathrm{~mm})$ & 40 & 40 & 40 & 40 \\
\hline Axial length of CFR, $L(\mathrm{~mm})$ & 30 & 30 & 30 & 30 \\
\hline Static radial clearance, $C_{0}(\mathrm{~mm})$ & 0.050 & 0.044 & 0.041 & 0.047 \\
\hline Orifice diameter, $d_{0}(\mathrm{~mm})$ & 1.0 & 1.0 & 1.0 & None \\
\hline Recess geometry & Square & \multicolumn{2}{|c|}{ Young Leaf Mark } & None \\
\hline Recess sweepback angle, $\theta_{s}(\mathrm{deg})$ & 0 & -45 & 45 & - \\
\hline Number of recesses, $N r$ & 4 & 4 & 4 & - \\
\hline Axial length of recess, $L r(\mathrm{~mm})$ & 10 & 10 & 10 & - \\
\hline Circumferential length of recess, $L c(\mathrm{~mm})$ & 10 & 10 & 10 & - \\
\hline Maximum recess depth, $h(\mathrm{~mm})$ & 1.0 & 1.0 & 1.0 & - \\
\hline Recess area ratio, $A r$ & 0.106 & 0.106 & 0.106 & - \\
\hline
\end{tabular}

recess geometry, the static radial clearance $\left(C_{0}\right)$ in $\mathrm{LN}_{2}$ and the sweepback angle of the recess leading edge $\left(\theta_{s}\right)$ are listed in Table 1. The journal surface is coated with $\mathrm{Cr}_{2} \mathrm{O}_{3}$ plasma spray film so that its surface seems to be black.

\subsection{Test procedure}

The test CFRs were operated at a rotational speed of up to $45,000 \mathrm{rpm}$ using the cryogenic flow visualization test apparatus [9] at the JAXA Kakuda Space Center. Figure 4 shows a photograph of the test apparatus. The rotor is supported by a pair of self-lubricated ball bearings cooled by cryogenic liquid and driven by a compact electric motor connected with one end of the rotor. The cryogenic liquid is sealed by a face contact metal-bellows mechanical seal and the test CFR. The clear case of the test CFR is also made of polycarbonate and the outer case of the test apparatus in the test CFR section is composed of a transparent plastic, acrylic acid

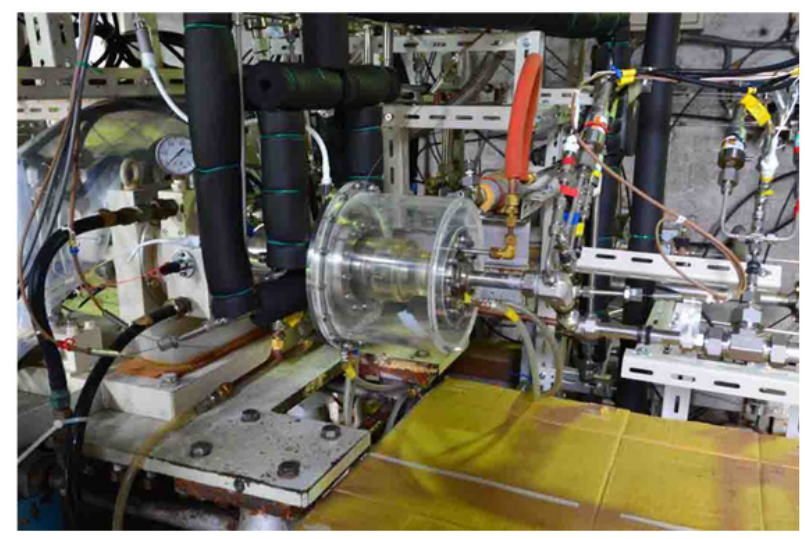

Fig. 4 Photograph of the test apparatus resin. The cavity between the clear case and the clear outer case is evacuated by a vacuum pump to create a heat insulation layer. The flow pattern in the CFR clearance was observed by two video cameras and a high-speed video camera installed in three radial directions. In the present study, liquid nitrogen $\left(\mathrm{LN}_{2}\right)$ was supplied to the test CFR with a pressure of up to 1.7 $\mathrm{MPa}$ to achieve a safe, easy operation. The main test conditions are listed in Table 2. Test conditions such as $\mathrm{LN}_{2}$ supply pressure were established to operate the test CFR at over 40,000 rpm based on a previous study [9]. The static pressure and the fluid temperature were measured at major points in the test CFR and the apparatus. The pressure fluctuations upstream and downstream of the CFR were also measured by a piezoelectric pressure sensor. Volumetric flow rate of $\mathrm{LN}_{2}$ was measured by a turbine flowmeter installed in the supply line leading to the test CFR.

The flow coefficient $\left(C_{f}\right)$ defined by Eq. (1) is introduced to evaluate the flow condition in the CFR clearance.

$$
C_{f}=\frac{Q}{\pi d C_{0}} \sqrt{\frac{\rho_{\text {sat }}}{2 \Delta P_{12}}}
$$

ere, $\rho_{\text {sat }}$ is the saturated density of $\mathrm{LN}_{2}$ at the upstream temperature $\left(T_{1}\right)$. Thus, the flow coefficient expresses the ratio of the flow speed at the outlet of the CFR clearance based on the measured volumetric flow rate $(Q)$ to the flow speed of saturated $\mathrm{LN}_{2}$ calculated from the pressure difference of the CFR $\left(\Delta P_{12}\right)$. The cavitation area ratio $(A c)$ defined by Eq. (2) is also introduced to evaluate the two-phase flow condition in the CFR clearance.

Table 2 Main test conditions

\begin{tabular}{|l|c|}
\hline $\mathrm{LN}_{2}$ supply pressure, $P_{1}(\mathrm{MPa})$ & $0.7-1.7$ \\
\hline Pressure difference of CFP, $\Delta P_{12}(\mathrm{MPa})$ & $0.6-1.6$ \\
\hline $\mathrm{LN}_{2}$ supply temperature, $T_{1}(\mathrm{~K})$ & $85-105$ \\
\hline $\mathrm{LN}_{2}$ supply flow rate, $Q(\ell / \mathrm{s})$ & $0.050-0.140$ \\
\hline Steady rotational speed, $N(\mathrm{rpm})$ & $20,000-45,000$ \\
\hline Sommerfeld number, $S$ & $0.46-1.03$ \\
\hline
\end{tabular}




$$
A c=\frac{4 a_{c}}{\pi d L}
$$

Here, $a_{c}$ is the cavitation cloud area within the clearance on the fourth of the CFR inner surface obtained from the snapshot of the video image. The flow coefficient and the cavitation area ratio were obtained for various values of the cavitation number $\left(\sigma_{p s}\right)$ defined by Eq. (3).

$$
\sigma_{p s}=\frac{P_{1}-P_{s a t}}{\Delta P_{12}+(1 / 2) \rho_{s a t} V_{\theta}^{2}}
$$

Here, $P_{\text {sat }}$ is the saturated pressure at $T_{1}$, and $V_{\theta}$ is the circumferential velocity of the journal outer surface. Thus, the value of $\sigma_{p s}$ takes into account the pressure drop and the flow speed of saturated $\mathrm{LN}_{2}$ induced by the journal rotation through the CFR clearance.

\section{Experimental results}

Four test series were carried out in the present study. The hours of operation for each test series are summarized in Table 3. An example of the state and properties of liquid nitrogen obtained for Type $\mathrm{D}$ is listed in Table 4. Liquid nitrogen is found to be in the saturated condition downstream of the test CFR. The standard deviations of the measured static pressure and temperature were less than $1 \%$ of their average values under the constant rotating condition.

Figure 5 shows the variations of the $C_{f}$, the $A c$ and the $T_{1}$ vs the rotational speed obtained for Type B. Flow visualization images obtained at (a) to (d) denoted in the Fig. 5 are shown in Fig. 6. The variations and the images for Type C, Type D and Type FR are also shown in Figs 7 to 12 . Since the journal surface is coated with $\mathrm{Cr}_{2} \mathrm{O}_{3}$ plasma spay film, it looks black in the image. When the cavitation occurs in the CFR clearance, it looks like a white cloud, i.e., a cavitation cloud, as shown in Figs. 6, 8, 10 and 12. Figure 13 shows the image of the cavitation cloud in the recess obtained for each type of the CFR with a recess. It is found that the cavitation cloud

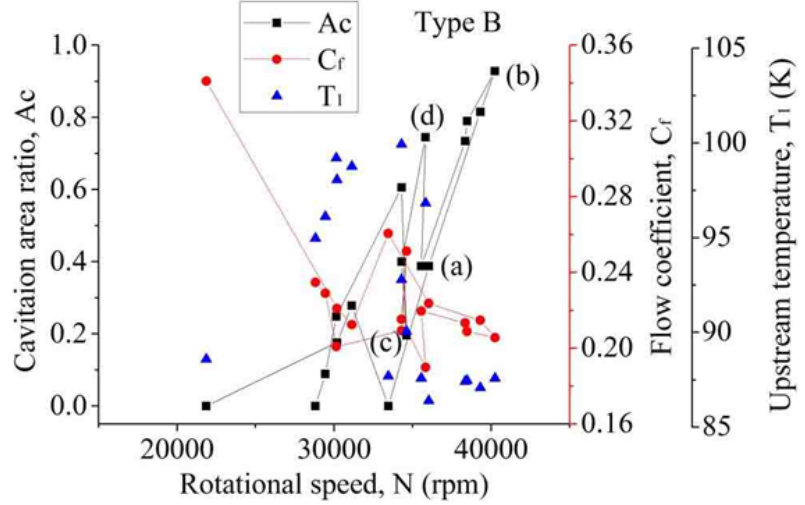

Fig. 5 Variations of the cavitation area ratio $(A c)$, the flow coefficient $\left(C_{f}\right)$ and the upstream temperature $\left(T_{1}\right)$ vs the rotational speed obtained for Type B

disappears near the recess edge on the downstream side and the leading and trailing edges in the journal rotating direction, especially in the tip area of each sharp edge. According to the high-speed video image $(20,000 \mathrm{fps})$, the flow pattern of the cavitation cloud is considered to be an unstable turbulent flow. Furthermore, it was confirmed that $\mathrm{LN}_{2}$ flowed out of the CFR clearance in the two-phase state independent of the rotational speed. The experimental results indicate that the value of $A c$ tends to increase with increasing rotational speed, and that the value of $C_{f}$ then tends to decrease with an increase in the rotational speed for each type of the CFR because of viscous frictional heating. However, a sudden change of $T_{1}$ seems to induce large variations of $A c$ and $C_{f}$ in the moderate speed operation independent of the CFR type.

\subsection{Steady state}

Firstly, the steady-state results obtained for $T_{1}<90 \mathrm{~K}$ in the high-rotational-speed operation are described. The effects of the recess geometry on the values of $A c$ and $C_{f}$ are shown in Fig. 14. Figure 14(a) shows the relationships between $A c$ and the rotational speed, and

Table 3 Hours of operation for sixteen tests

\begin{tabular}{|c|c|c|c|c|}
\hline Test series No. & 1 & 2 & 3 & 4 \\
\hline Test CFR & Type B & Type C & Type D & Type FR \\
\hline Recess geometry & Square & \multicolumn{2}{|c|}{ Young Leaf Mark } & None \\
\hline Total time, (s) & 1,859 & 1,934 & 1,988 & 1,844 \\
\hline Over 30,000 rpm, (s) & 1,053 & 901 & 959 & 761 \\
\hline Number of starts and stops & 4 & 4 & 4 & 4 \\
\hline
\end{tabular}

Table 4 State and properties of liquid nitrogen $\left(\mathrm{LN}_{2}\right)$ obtained for Type D $(N=37.3 \mathrm{krpm}, A c=0.919)$

\begin{tabular}{|c|c|c|}
\hline Location & Upstream & Downstream \\
\hline Pressure $(\mathrm{MPa})$ & 1.40 & 0.13 \\
\hline Temperature $(\mathrm{K})$ & 88.6 & 79.4 \\
\hline Density, $\rho\left(\mathrm{kg} / \mathrm{m}^{3}\right)$ & 757.3 & 799.0 \\
\hline Viscosity, $\mu(\mu \mathrm{Pa} \cdot \mathrm{s})$ & 105.4 & 140.7 \\
\hline
\end{tabular}



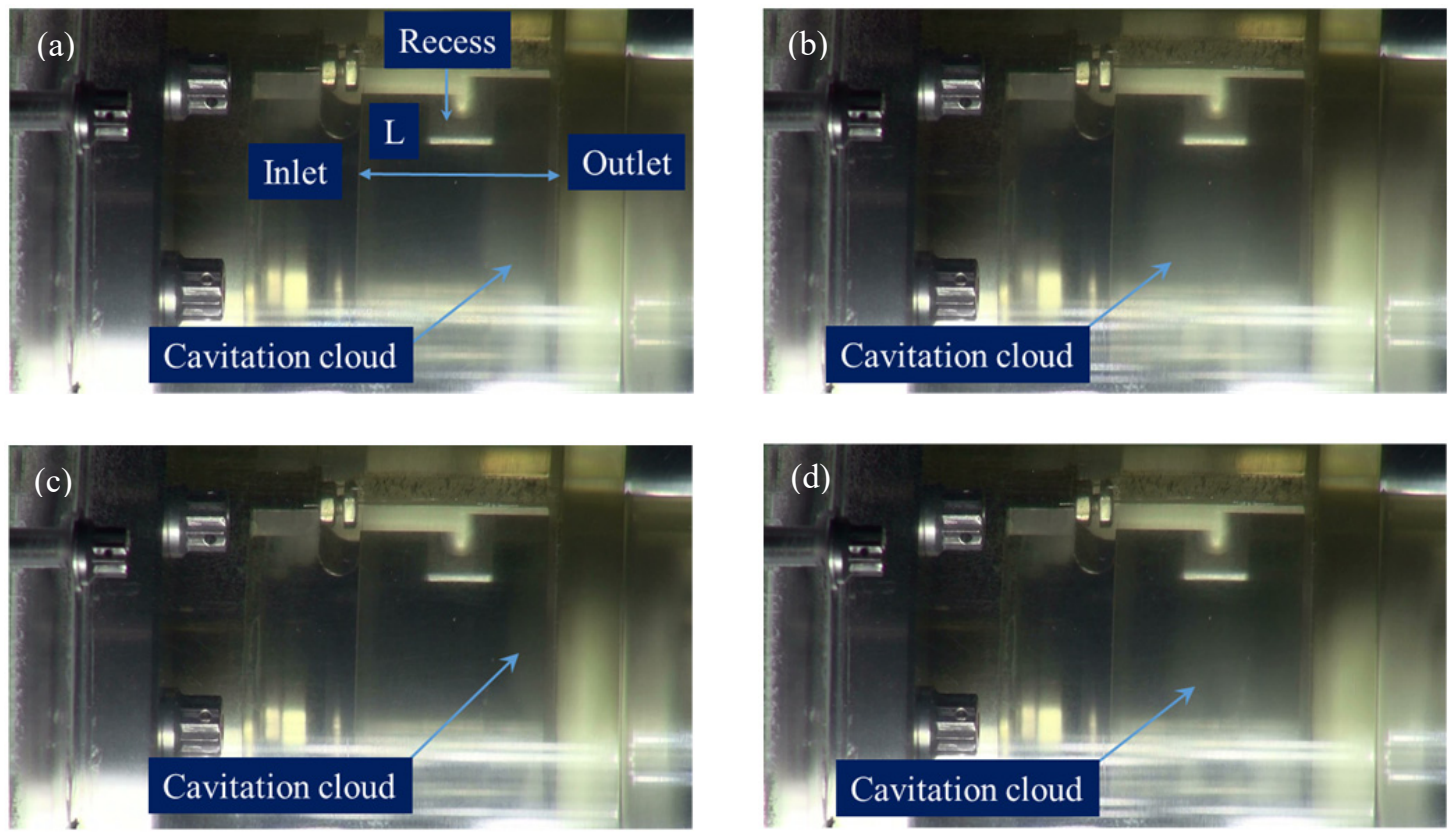

Fig. 6 Visualization images obtained at the (a) to (d) denoted in Fig. 5 for Type B

(a) $N=36.0 \mathrm{krpm}, T_{1}=86.0 \mathrm{~K}, \sigma_{p s}=0.356, C_{f}=0.244, A c=0.388$

(b) $N=40.2 \mathrm{krpm}, T_{1}=87.2 \mathrm{~K}, \sigma_{p s}=0.309, C_{f}=0.206, A c=0.928$

(c) $N=34.6 \mathrm{krpm}, T_{1}=90.7 \mathrm{~K}, \sigma_{p s}=0.332, C_{f}=0.251, A c=0.196$

(d) $N=35.8 \mathrm{krpm}, T_{1}=96.8 \mathrm{~K}, \sigma_{p s}=0.297, C_{f}=0.190, A c=0.745$

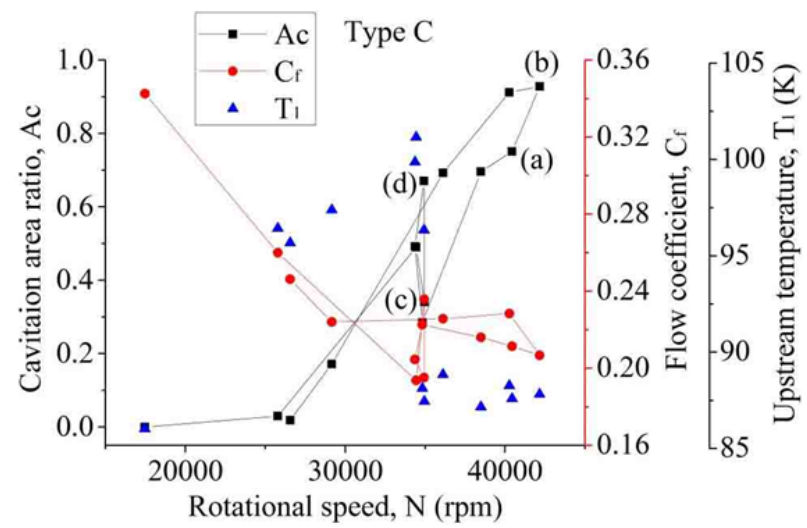

Fig. 7 Variations of the cavitation area ratio $(A c)$, the flow coefficient $\left(C_{f}\right)$ and the upstream temperature $\left(T_{1}\right)$ vs the rotational speed obtained for Type $\mathrm{C}$

$C_{f}$ obtained for each type of the CFR. The relationships to the value of $\sigma_{p s}$ are also shown in Fig. 14(b). Each solid line represents a fitting curve. The value of $A c$ obtained for each type of CFR tends to increase with increasing rotational speed, i. e., decreasing $\sigma_{p s}$ for up to $A c=1$, while the value of $C_{f}$ tends to decrease. The values of $C_{f}$ obtained for Type FR without a recess are much smaller than those for the other types of the CFR because of no source flow from the recess. Comparison of $A c$ at the same value of $\sigma_{p s}$ indicates that the average value of Type $\mathrm{D}$ is larger than that of Type $\mathrm{B}$, which is larger than that of Type $\mathrm{C}$, and that the difference between them tends to be smaller as the cavitation number decreases. On the other hand, the average value of $C_{f}$ for Type $\mathrm{D}$ is smaller than that of Type $\mathrm{C}$ in the high $\sigma_{p s}$ condition where the average value of $C_{f}$ obtained for Type $\mathrm{B}$ is located in the middle range between those of Type D and Type C. However, distinct differences among them are found to disappear in the low $\sigma_{p s}$ condition. These facts indicate that the flow characteristic in the CFR clearance was affected by the recess geometry even at the same value of $\sigma_{p s}$ in the relatively high $\sigma_{p s}$ condition.

Figure 15(a) shows the relationships between $A c$ and $C_{f}$ for each type of the CFR. Since two-phase flow of $\mathrm{LN}_{2}$ occurred at the clearance outlet independent of the rotational speed, the $C_{f}$ showed a considerably low value even if $A c=0$. The values of $C_{f}$ basically tend to decrease with the increase in $A c$. The $C_{f}$ values obtained for $T_{1}<90 \mathrm{~K}$ in the high-rotational-speed operation are plotted against the $A c$ values for each type of the CFR in Fig. 15(b). Each solid line represents a fitting curve. According to the fitting curves, the value of $C_{f}$ obtained for each type of CFR tends to decrease with increasing $A c$, and the $C_{f}$ value of Type FR without the recess is confirmed to be much smaller than those of the CFRs with the recess independent of the $A c$ value. Since the sonic speed of the cavitaing flow drastically decreases, the cavitating flow is considered to be choked at the clearance outlet. Therefore, the flow coefficient $\left(C_{f}\right)$ is denoted by Eq. (4). 

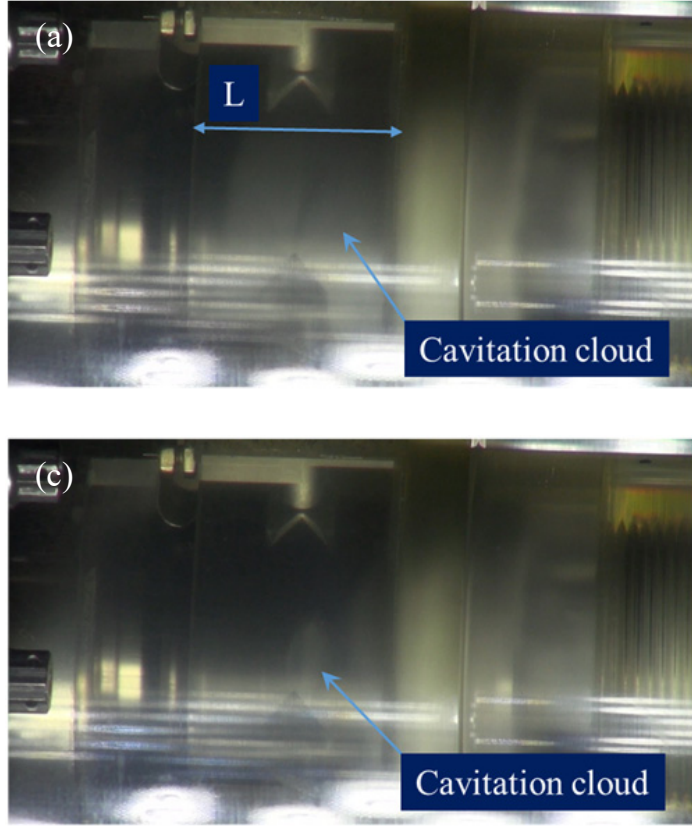
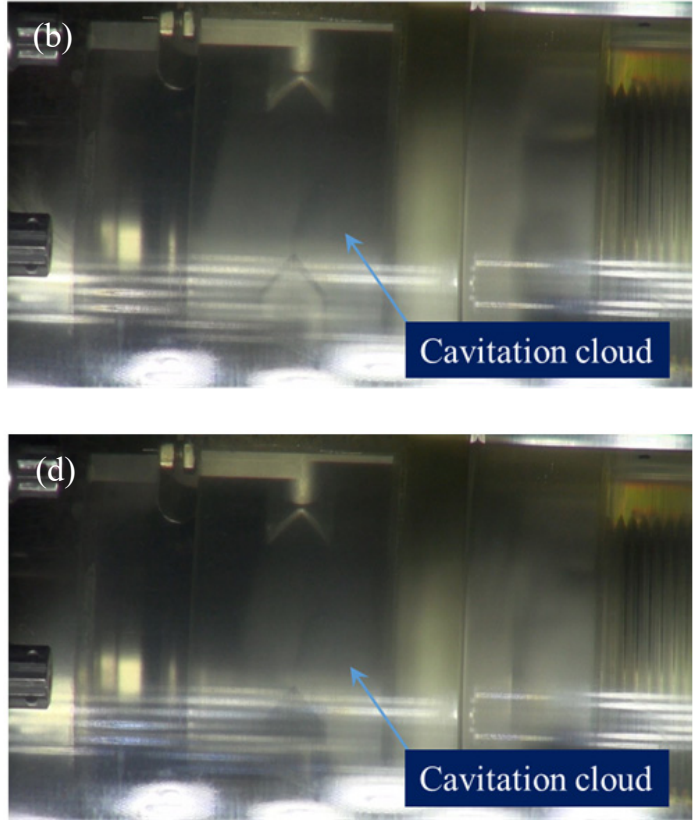

Fig. 8 Visualization images obtained at the (a) to (d) denoted in Fig. 7 for Type $\mathrm{C}$

(a) $N=40.4 \mathrm{krpm}, T_{1}=87.3 \mathrm{~K}, \sigma_{p s}=0.317, C_{f}=0.211, A c=0.751$

(b) $N=42.2 \mathrm{krpm}, T_{1}=87.8 \mathrm{~K}, \sigma_{p s}=0.299, C_{f}=0.207, A c=0.928$

(c) $N=34.9 \mathrm{krpm}, T_{1}=87.1 \mathrm{~K}, \sigma_{p s}=0.362, C_{f}=0.236, A c=0.341$

(d) $N=34.9 \mathrm{krpm}, T_{1}=96.3 \mathrm{~K}, \sigma_{p s}=0.302, C_{f}=0.195, A c=0.671$

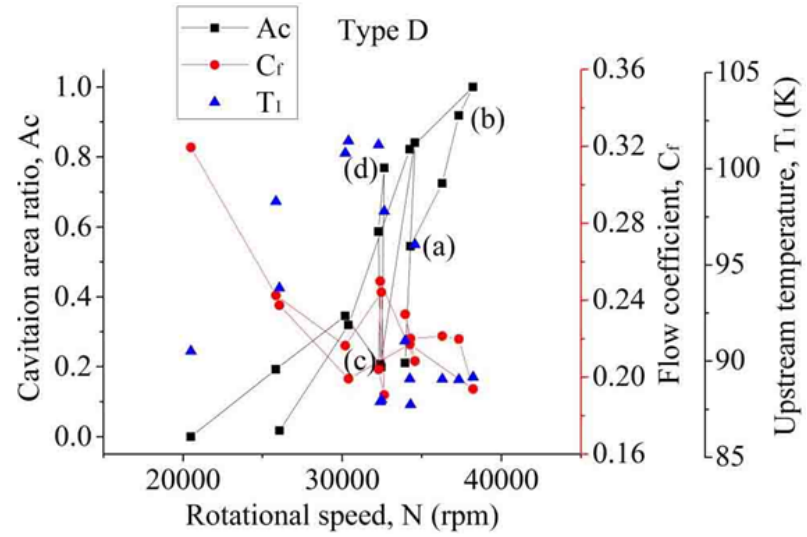

Fig. 9 Variations of the cavitation area ratio $(A c)$, the flow coefficient $\left(C_{f}\right)$ and the upstream temperature $\left(T_{1}\right)$ vs the rotational speed obtained for Type D

$$
C_{f}=\frac{\rho_{m} a_{m}}{\rho_{0}} \sqrt{\frac{\rho_{\text {sat }}}{2 \Delta P_{12}}}
$$

Here, $\rho_{m}$ is the mixture density of vapor and liquid two-phase flow at the clearance outlet, $a_{m}$ is the sonic speed of the cavitating flow at the outlet, and $\rho_{0}$ is the density of $\mathrm{LN}_{2}$ at the turbine flowmeter. When the isothermal process without the thermodynamic effect of cavitation is assumed, the values of $\rho_{m}$ and $a_{m}$ are obtained from a void fraction $(\alpha)$ of the cavitating flow at the clearance outlet by using Eqs. $(5,6)[10]$ :

$$
\begin{aligned}
& \rho_{m}=\alpha \rho_{v}+(1-\alpha) \rho_{l} \\
& a_{m}=a_{v}\left[\kappa\left\{\alpha^{2}+\alpha(1-\alpha) \frac{\rho_{l}}{\rho_{v}}\right\}\right]^{-0.5}
\end{aligned}
$$

where $\rho_{v}$ and $\rho_{l}$ are nitrogen saturated densities of vapor and liquid phases at the clearance outlet, and $\kappa$ is the specific heat ratio of nitrogen. Thus, the value of $C_{f}$ can be considered to depend mainly on the void fraction and the saturated temperature $\left(T_{\text {out }}\right)$ or pressure of nitrogen at the outlet plane of the CFR clearance. Figure 16 shows the relationships between the void fraction and the sonic speed at the outlet and those between the $C_{f}$ value obtained for $\Delta P_{12}=1.5 \mathrm{MPa}$ and the outlet saturated temperature range of $T_{\text {out }}=78-86 \mathrm{~K}$ by using Eqs. (4-6) based on the experimental results. The average value of $C_{f}$ obtained for the CFRs with the recess is about 0.21 at $A c=0.8$ and that of Type FR is about 0.16 , as shown in Fig. 14(b). According to the results shown in Fig. 15, if the difference of $T_{\text {out }}$ between them is less than $2 \mathrm{~K}$, the $\alpha$ value of Type FR at the outlet is found to be about 0.1 larger than those of the CFRs with the recess. Furthermore, the maximum difference of $C_{f}$ between Type $\mathrm{C}$ and Type D near $\sigma_{p s}=$ 0.36 is found to be about $0.02(=0.24-0.22)$ in Fig. 14(b), which indicates that the recess geometry difference caused an increase of about 0.04 in the void fraction at the clearance outlet. 

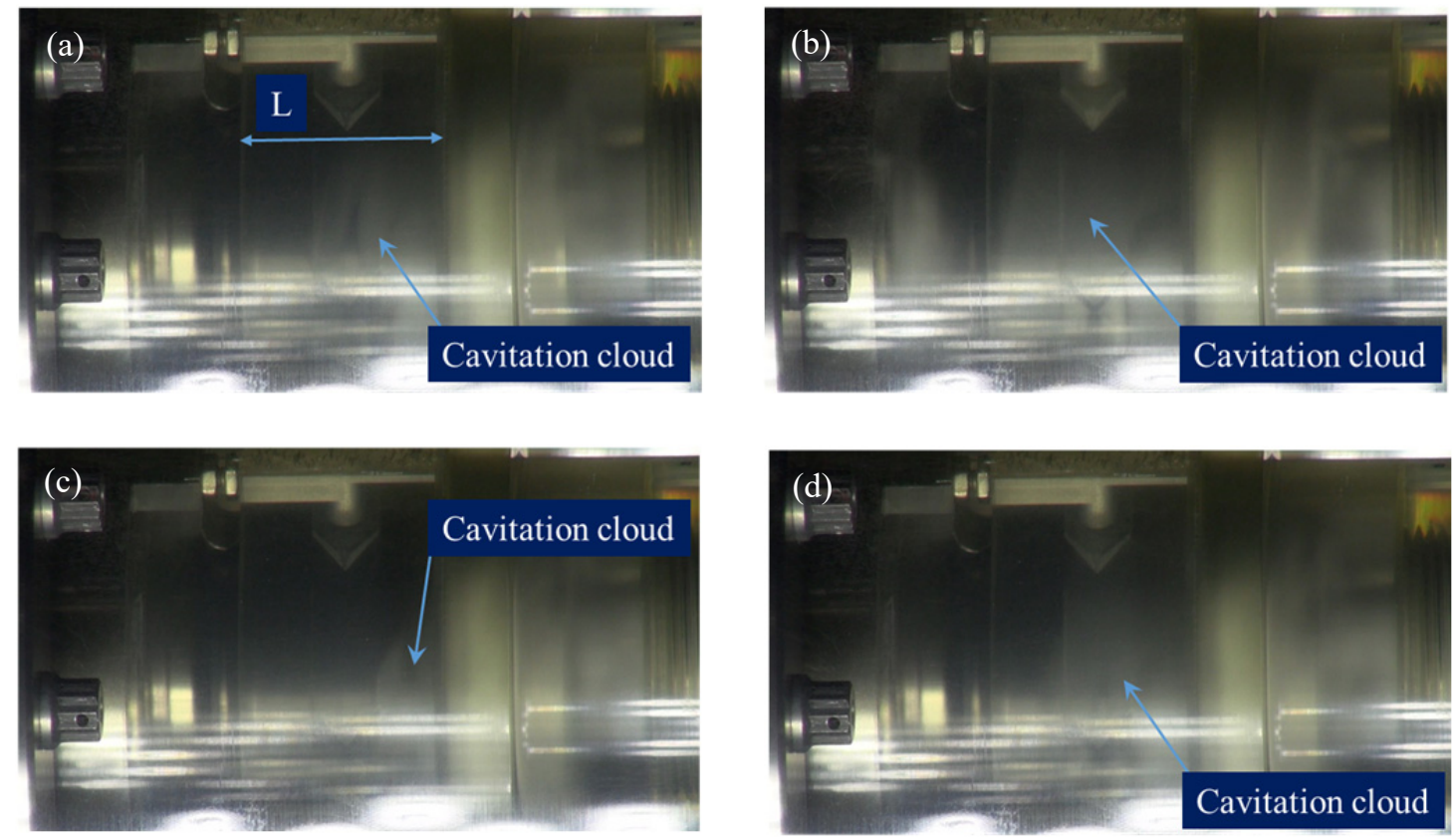

Fig. 10 Visualization images obtained at the (a) to (d) denoted in Fig. 9 for Type D
(a) $N=34.3 \mathrm{krpm}, T_{1}=87.4 \mathrm{~K}, \sigma_{p s}=0.383, C_{f}=0.220, A c=0.545$
(b) $N=37.3 \mathrm{krpm}, T_{1}=88.6 \mathrm{~K}, \sigma_{p s}=0.297, C_{f}=0.220, A c=0.919$
(c) $N=32.5 \mathrm{krpm}, T_{1}=87.6 \mathrm{~K}, \sigma_{p s}=0.406, C_{f}=0.244, A c=0.199$
(d) $N=32.6 \mathrm{krpm}, T_{1}=96.3 \mathrm{~K}, \sigma_{p s}=0.333, C_{f}=0.191, A c=0.769$

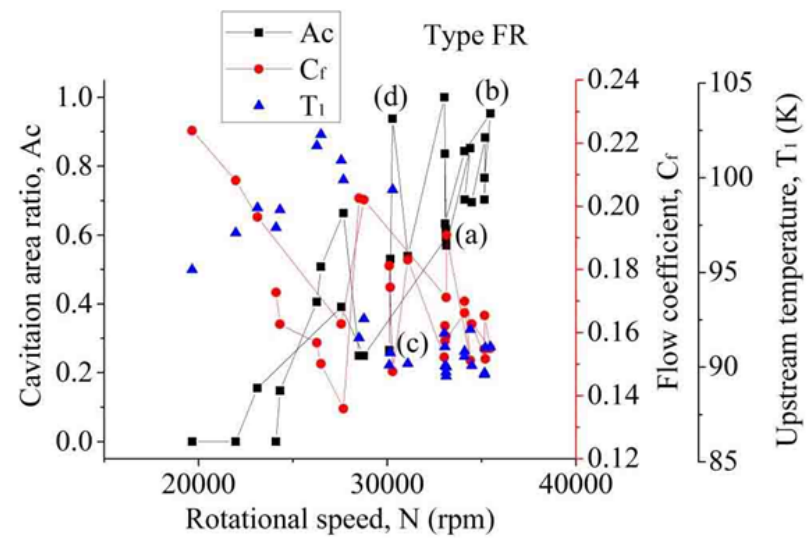

Fig. 11 Variations of the cavitation area ratio $(A c)$, the flow coefficient $\left(C_{f}\right)$ and the upstream temperature $\left(T_{1}\right)$ vs the rotational speed obtained for Type FR

\subsection{Transient state}

The influence of the sudden change of the upstream temperature $\left(T_{1}\right)$ of $\mathrm{LN}_{2}$ on the flow condition in the clearance of the CFR was investigated under the condition of a constant rotational speed. As shown by (c) and (d) denoted in Figs 5, 7, 9 and 11, a sudden rise in the upstream temperature $\left(\Delta T_{1}\right)$ occurred in the moderate speed operation independent of the CFR type, which induced a drop in the cavitation number $\left(\sigma_{p s}\right)$ and consequently induced a rise in the cavitation area ratio $(\Delta A c)$ and a drop in the flow coefficient $\left(\Delta C_{f}\right)$. Figure
17 shows the effect of the sudden rise in the upstream temperature on the cavitation area ratio and the flow coefficient for each type of the CFR. Figure 17(a) shows the relationships between $\Delta T_{1}$ normalized by the Stepanoff's factor B $\left(T^{*}\right)[11]$ and $\Delta A c$, and $\Delta C_{f}$ divided by the average $\left(C_{f m}\right)$ of those before and after $\Delta T_{1}$. The normalized $\Delta T_{1}{ }^{*}$ is defined by Eq. (7):

$$
\Delta T_{1}^{*}=\frac{\Delta T_{1}}{T^{*}}=\Delta T_{1} \frac{\rho_{l} C_{p l}}{\rho_{v} L_{h}}
$$

where $\rho_{v}$ and $\rho_{l}$ are saturated densities of vapor and liquid phases, $C_{p l}$ is the specific heat at constant pressure, and $L_{h}$ is the latent heat at $T_{1}$ before the rise. The values of $\Delta A c$ and $\Delta C_{f} / C_{f m}$ are also plotted against the drop in the cavitation number $\left(\Delta \sigma_{p s}\right)$ induced by $\Delta T_{1}$ in Fig. 17 (b). Figure 17 shows that the values of $\Delta A c$ and $\Delta C_{f} / C_{f m}$ depend on the recess configuration including no recess. However, these values are found to increase basically with increasing $\Delta \sigma_{p s}$, except for Type $\mathrm{C}$ in Fig. 17 (b). Comparison between Type $\mathrm{C}$ and Type $\mathrm{D}$ at the same value of $\Delta T_{1}{ }^{*}$ or $\Delta \sigma_{p s}$ indicates that both the $\Delta A c$ and $\Delta C_{f} / C_{f m}$ values of Type D are considerably larger than those of Type $\mathrm{C}$. Therefore, the pressure distribution within the clearance of Type $\mathrm{C}$ can be considered to be higher than that of Type D, which is correspondent with the steady-state results shown in Fig. 14.

\section{Discussion}

The sweepback angle of the recess leading edge $\left(\theta_{s}\right)$ 

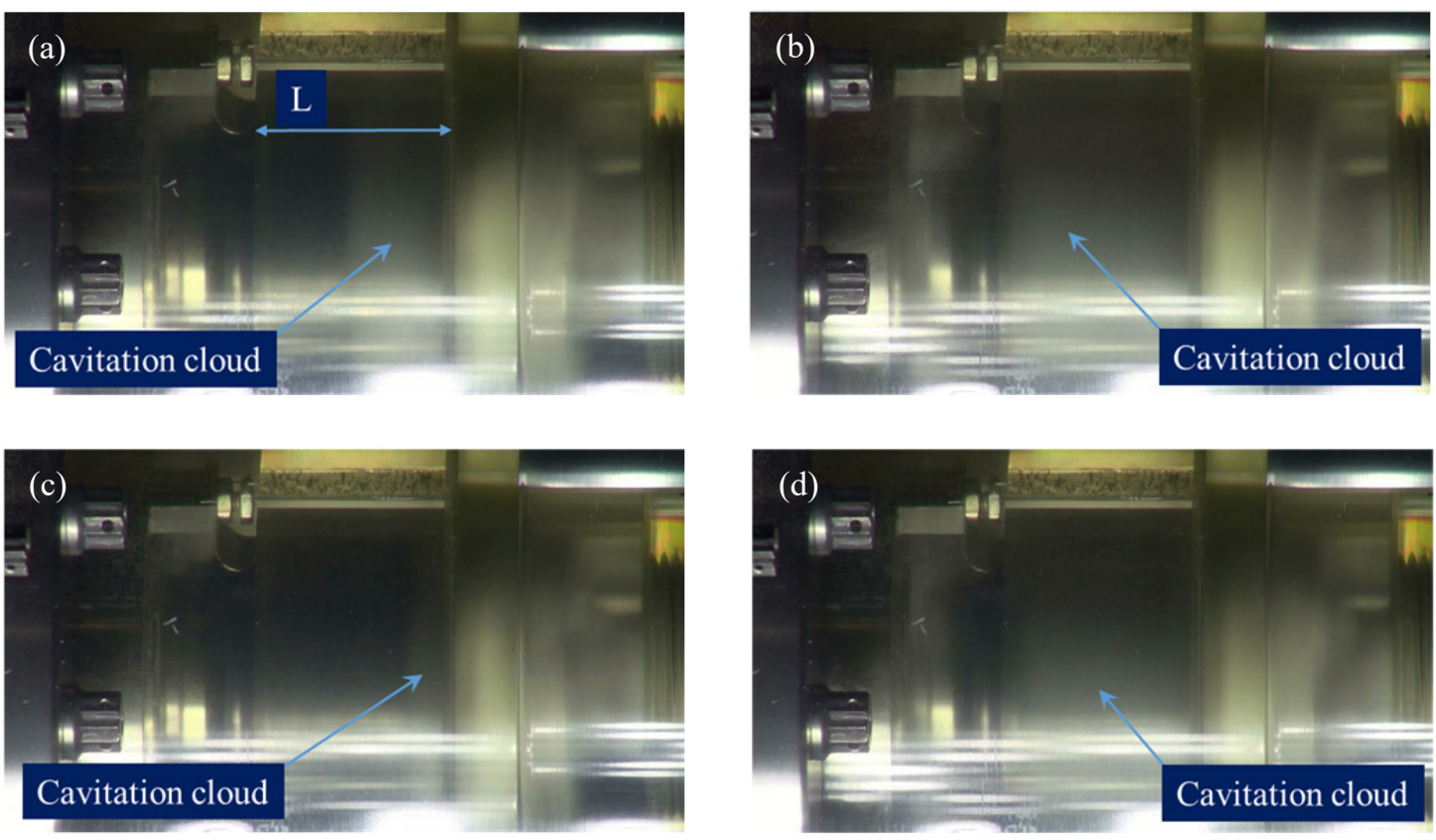

Fig. 12 Visualization images obtained at the (a) to (d) denoted in Fig. 11 for Type FR
(a) $N=33.1 \mathrm{krpm}, T_{1}=89.2 \mathrm{~K}, \sigma_{p s}=0.364, C_{f}=0.171, A c=0.593$
(b) $N=33.5 \mathrm{krpm}, T_{1}=90.0 \mathrm{~K}, \sigma_{p s}=0.336, C_{f}=0.155, A c=0.953$
(c) $N=30.1 \mathrm{krpm}, T_{1}=89.4 \mathrm{~K}, \sigma_{p s}=0.401, C_{f}=0.181, A c=0.266$
(d) $N=30.3 \mathrm{krpm}, T_{1}=97.1 \mathrm{~K}, \sigma_{p s}=0.323, C_{f}=0.148, A c=0.938$
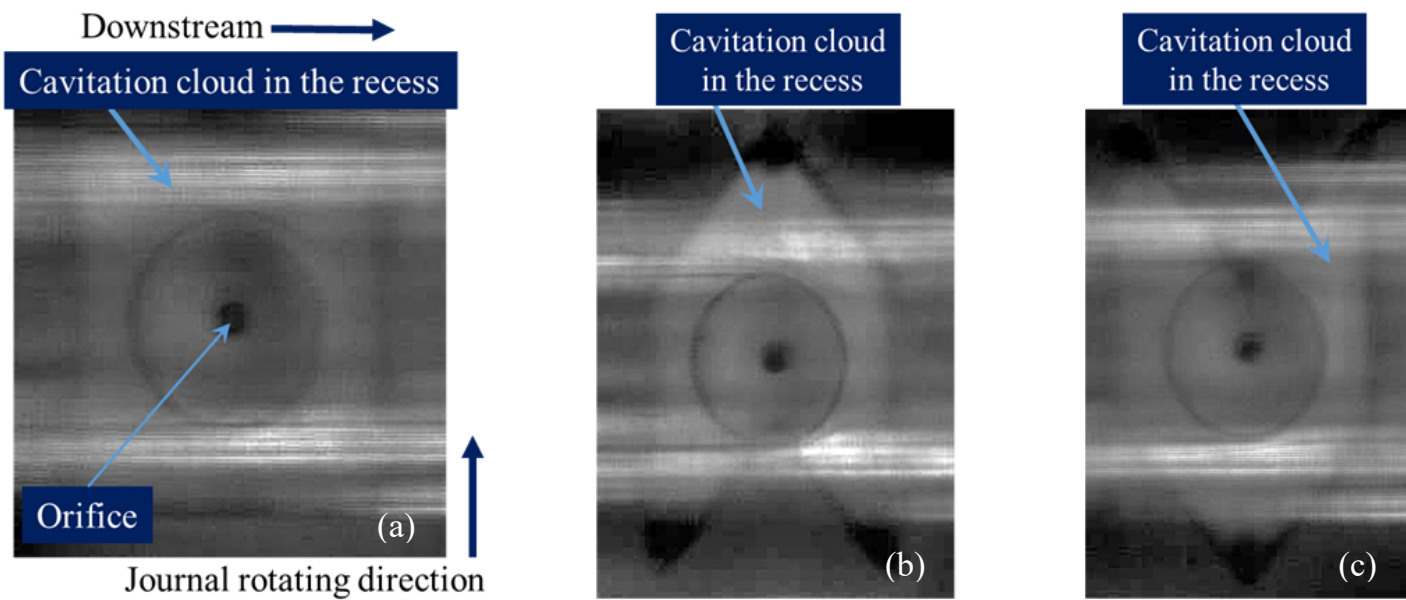

Fig. 13 High-speed video images of the cavitation cloud in the recess obtained for 20,000 fps
(a) $N=40.2 \mathrm{krpm}, T_{1}=87.2 \mathrm{~K}, \sigma_{p s}=0.309, C_{f}=0.206, A c=0.928$, Type B
(b) $N=42.2 \mathrm{krpm}, T_{1}=87.8 \mathrm{~K}, \sigma_{p s}=0.299, C_{f}=0.207, A c=0.928$, Type C
(c) $N=37.3 \mathrm{krpm}, T_{1}=88.6 \mathrm{~K}, \sigma_{p s}=0.297, C_{f}=0.220, A c=0.919$, Type D

shown in Fig. 1 is introduced to express the differences between Type B, C and D, i. e., $\theta_{s}=-45 \mathrm{deg}$. for Type C, $\theta_{s}=0 \mathrm{deg}$. for Type $\mathrm{B}$ and $\theta_{s}=45 \mathrm{deg}$. for Type $\mathrm{D}$. Based on the fitting curves in Fig. 14, the values of $A c$ and $C_{f}$ are obtained at the same rotational speed and plotted against the sweepback angle of the recess leading edge in Fig. 18 (a), and those obtained at the same cavitation number $\sigma_{p s}$ are also plotted against $\theta_{s}$ in Fig. 18 (b). The value of $A c$ at the same rotational speed for each type of the CFR is found to increase monotonically with the increase in $\theta_{s}$, while the value of
$C_{f}$ is found to decrease monotonically with the increase in $\theta_{s}$, which indicates that the flow condition depends strongly on the sweepback angle of the recess leading edge in the high-rotational-speed operation. However, the distinct differences between them tend to decrease with increasing rotational speed or decreasing $\sigma_{p s}$ because their $A c$ values approach 1. Figure 19 shows the relationships between the sweepback angle of the recess leading edge and the rise in the cavitation area ratio $(\triangle A c)$, and the drop ratio of the flow coefficient $\left(\Delta C_{f} /\right.$ $C_{f m}$ ) induced by the sudden rise in the upstream 

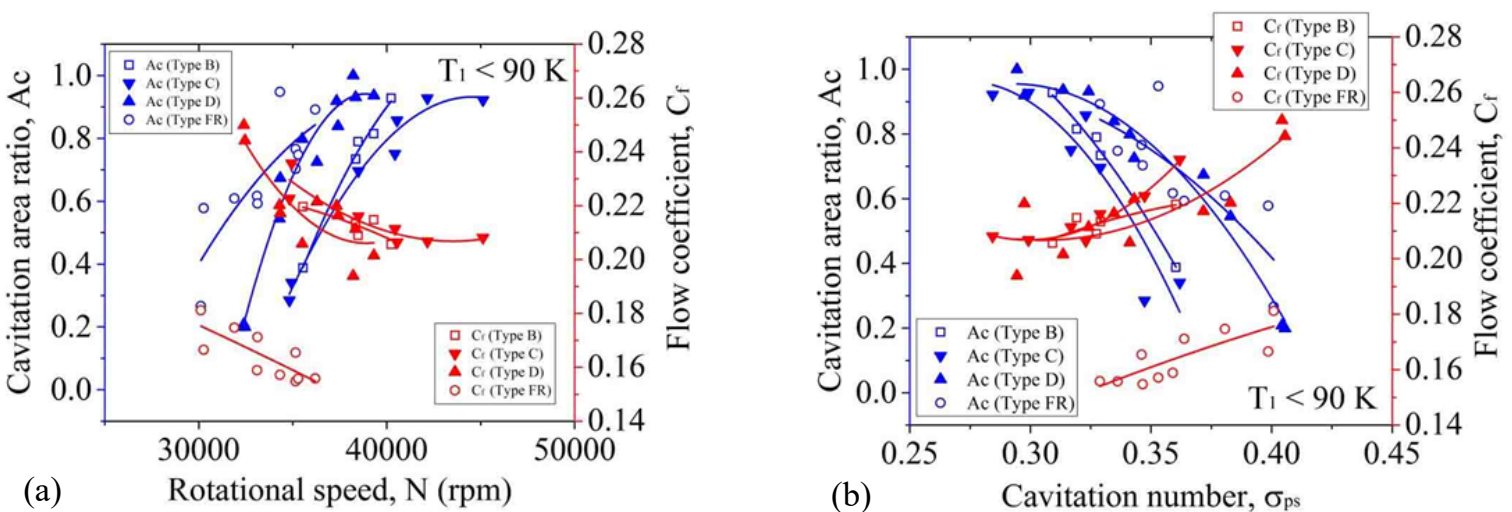

Fig. 14 Effect of the recess geometry on the cavitation area ratio $(A c)$ and the flow coefficient $\left(C_{f}\right)$ obtained for $T_{1}<90 \mathrm{~K}$ in the high-rotational-speed operation

(a) Variations of the cavitation area ratio $(A c)$ and the flow coefficient $\left(C_{f}\right)$ vs the rotational speed

(b) Variations of the cavitation area ratio $(A c)$ and the flow coefficient $\left(C_{f}\right)$ vs the cavitation number $\left(\sigma_{p s}\right)$
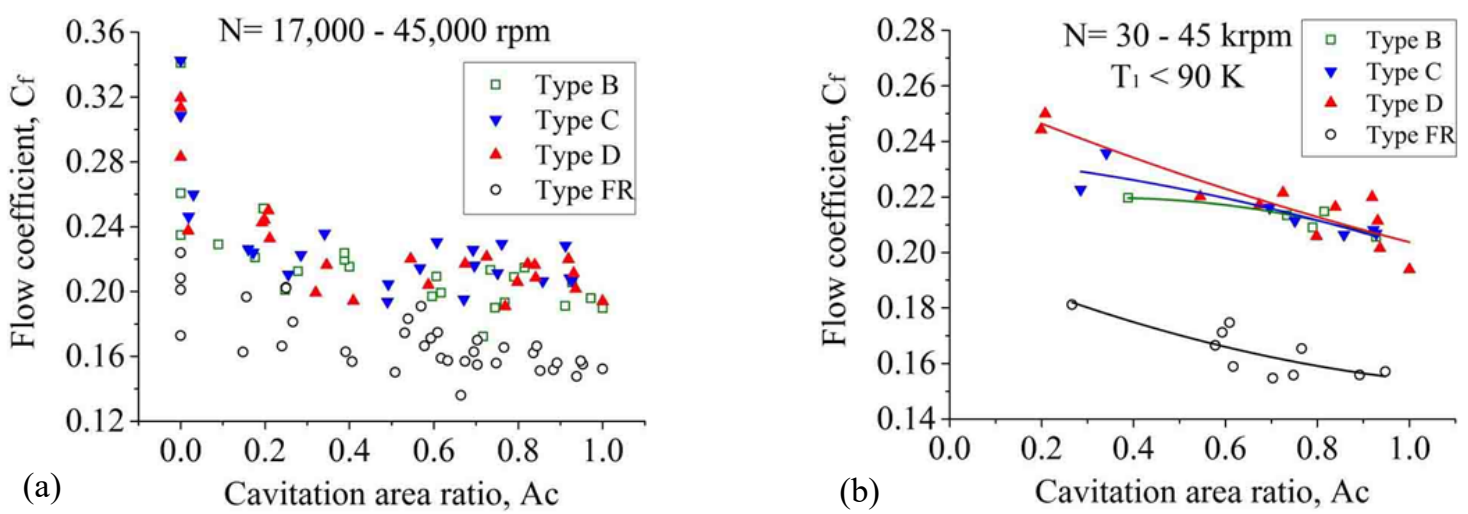

Fig. 15 Relationships between the flow coefficient and the cavitation area ratio

(a) Variations of the flow coefficient $\left(C_{f}\right)$ vs the cavitation area ratio $(A c)$

(b) Variations of the flow coefficient $\left(C_{f}\right)$ vs the cavitation area ratio $(A c)$ obtained for $T_{1}<90 \mathrm{~K}$ in the high-rotational-speed operation

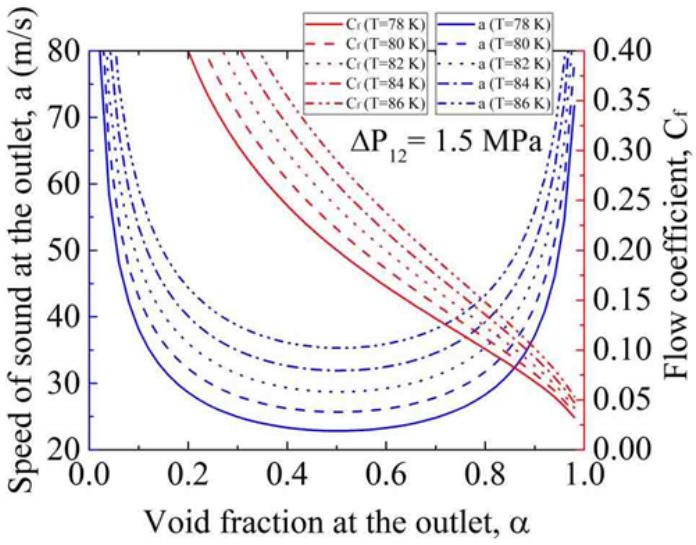

Fig. 16 Relationships between the void fraction and the sonic speed at the outlet plane of the clearance, and the $C_{f}$ value obtained for $\Delta P_{12}=1.5 \mathrm{MPa}$ and the outlet saturated temperature range of $T_{\text {out }}=$ 78-86 K by using Eqs. (4-6)

temperature $\left(\Delta T_{1}\right)$. Each solid line represents a fitting curve. The average values of $\Delta A c$ and $\Delta C_{f} / C_{f m}$ are found to increase monotonically with the increase in $\theta_{s}$, which indicates that the flow condition depends strongly on the sweepback angle of the recess leading edge.

The upstream boundary between the liquid phase and the cavitation cloud within the clearance may be considered to present a kind of contour line of the highest saturated pressure. As shown in Fig. 18, comparisons of $A c$ not only at the same rotational speed but also at the same value of $\sigma_{p s}$ show that $A c$ of Type D is always larger than those of Type $\mathrm{B}$ and Type $\mathrm{C}$, which indicates that the pressure drop of Type $\mathrm{D}$ in the liquid phase within the clearance is larger than those of Type B and Type $\mathrm{C}$. According to the visualization images in Figs 6,8 and 10 , the rise in the cavitation area ratio induced by $\Delta T_{1}$ is found to be caused by the growth of the cavitation area from downstream to upstream of the recess area, which indicates that the value of $\triangle A C$ depends on the pumping effect of the recess. Therefore, the $\triangle A C$ value of Type $\mathrm{C}$ is considerably smaller than that of Type $\mathrm{D}$, which means that the recess pumping effect of Type $\mathrm{C}$ is stronger than that of Type D. These results obtained in the steady-state and the transientstate can be considered to demonstrate that the pumping effect of the recess induced by the interaction between 

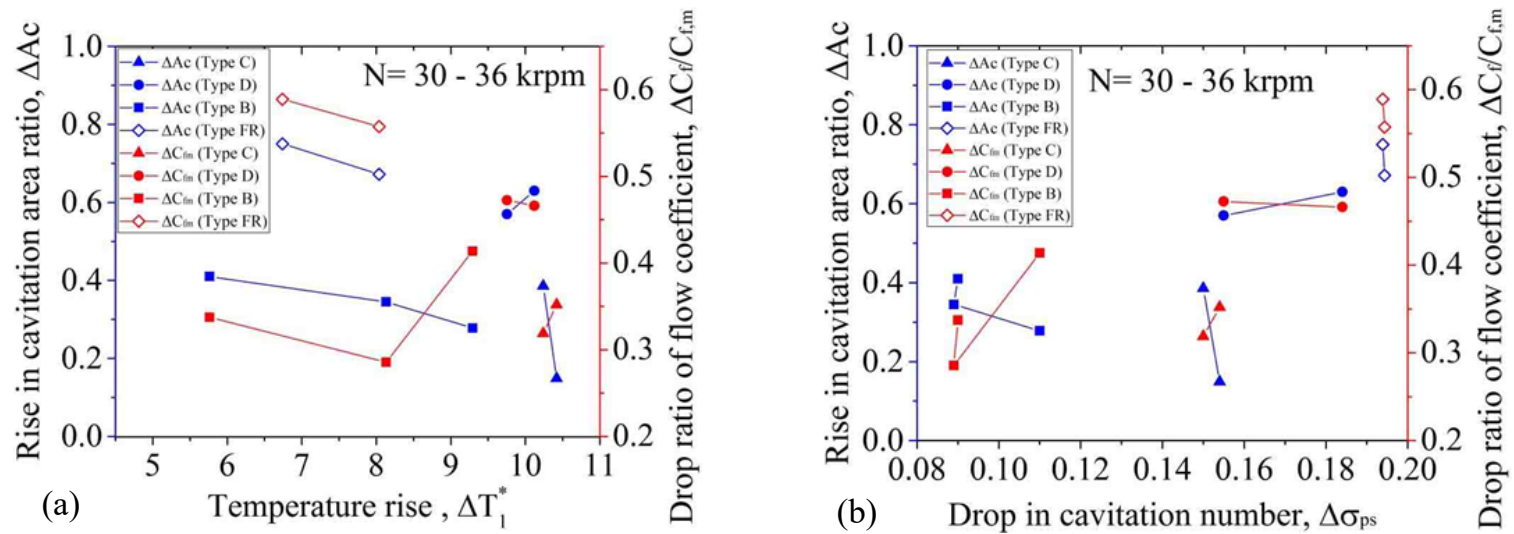

Fig. 17 Effect of the sudden rise in the upstream temperature $\left(\Delta T_{1}\right)$ on the cavitation area ratio and the flow coefficient

(a) Relationships between $\Delta T_{1}$ normalized by the Stepanoff's factor B $\left(T^{*}\right)$ and $\Delta A c$, and $\Delta C_{f}$ divided by the average $\left(C_{f m}\right)$ of those before and after $\Delta T_{1}$

(b) Relationships between drop in the cavitation number $\left(\Delta \sigma_{p s}\right)$ induced by $\Delta T_{1}$ and $\Delta A c$, and $\Delta C_{f}$ divided by the average $\left(C_{f m}\right)$ of those before and after $\Delta T_{1}$

(a)

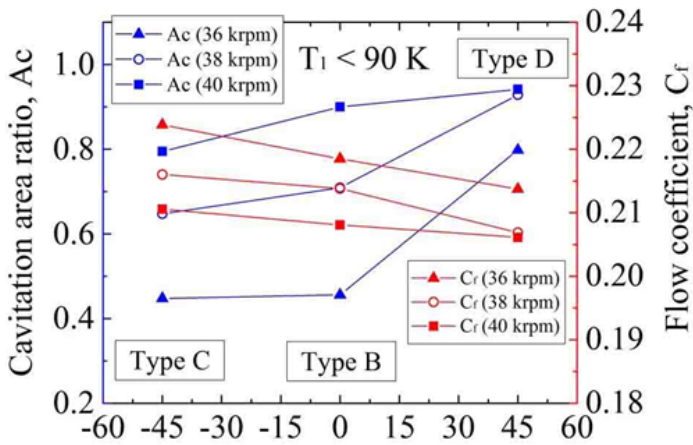

Sweepback angle of recess leading edge, $\theta_{\mathrm{s}}(\mathrm{deg})$ (b)

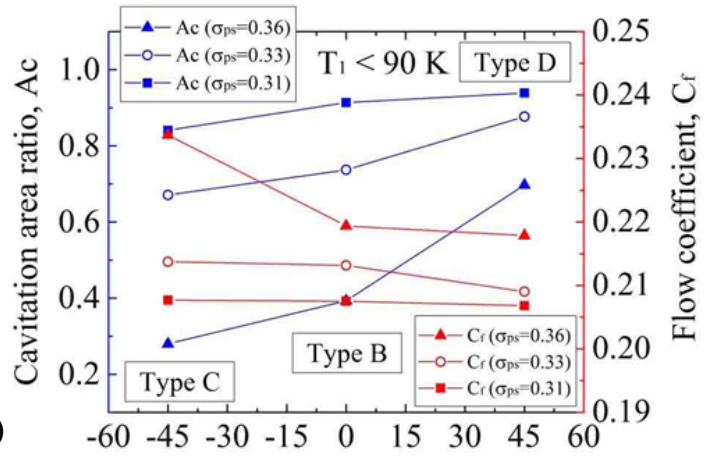

Sweepback angle of recess leading edge, $\theta_{\mathrm{s}}(\mathrm{deg})$

Fig. 18 Effect of the sweepback angle of the recess leading edge $\left(\theta_{s}\right)$ on the flow characteristics (a) Comparison at the same rotational speed (b) Comparison at the same cavitation number $\left(\sigma_{p s}\right)$

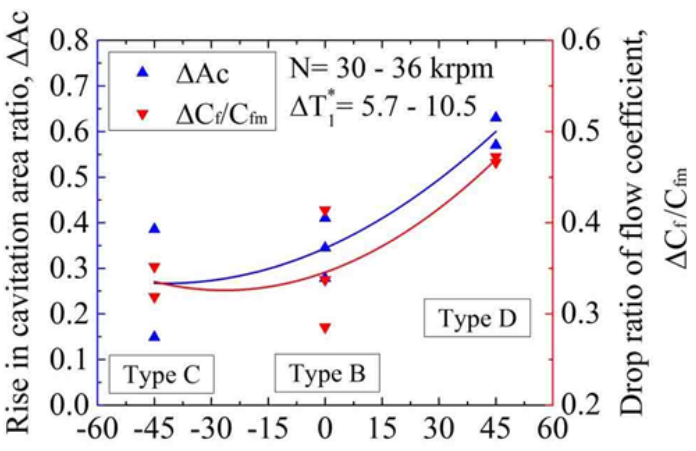

Sweepback angle of recess leading edge, $\theta_{\mathrm{s}}(\mathrm{deg})$

Fig. 19 Effect of the sweepback angle of the recess leading edge $\left(\theta_{s}\right)$ on the rise in the cavitation area ratio $(\triangle A c)$, and the drop ratio of the flow coefficient $\left(\Delta C f / C_{f m}\right)$ induced by the sudden rise in the upstream temperature $\left(\Delta T_{1}\right)$

the source flow from the recess and the rotating flow caused by the journal rotation is stronger in Type $\mathrm{C}$ than in Type D. In general this feature would be easily predicted by the results obtained for the herringbone grooved journal bearings [12]. However, the strong pumping effect induced by the recess leading edge of Type $\mathrm{C}$ may produce a large pressure fluctuation in the circumferential direction on the bearing inner surface, which seems to excite journal vibration for the cryogenic HJB.

\section{Conclusions}

A flow visualization experiment in the clearance between a clear floating-ring (CFR) and a rotating journal was carried out in order to clarify the effect of the sweepback angle of the recess leading edge $\left(\theta_{s}\right)$ on the flow characteristics. Four types of CFR with different recess geometries, i. e., the Young Leaf Mark, the square and non-recessed geometries, were operated at a rotational speed of up to $45,000 \mathrm{rpm}$ using liquid nitrogen $\left(\mathrm{LN}_{2}\right)$ to observe the interaction between the source flow from the recess and the rotating flow induced 
by the journal rotation in the clearance. The influence of the $\theta_{s}$ value on the flow characteristics was investigated by the comparing flow coefficient $\left(C_{f}\right)$ and the cavitation cloud area ratio $(A c)$ obtained from the visual image. Based on the experimental results, the dependence of the flow characteristics on the rotational speed was confirmed to be affected by the sweepback angle of the recess leading edge. The results obtained in the steady-state and the transient-state demonstrated that the pumping effect of the recess induced by the interaction between the source flow from the recess and the rotating flow caused by the journal rotation is stronger in Type $C$ than in Type D. Therefore, it may be considered that the influences of the recess geometry on the cryogenic HJBs are caused mainly by the effect of the sweepback angle of the recess leading edge on the flow condition.

\section{Acknowledgments}

This work was supported by the Japan Society for the Promotion of Science under Grant-in-Aid for Scientific Research (C) 25420128. The authors would like to thank Shun Kanno and Akihiro Tanno for their cooperation in carrying out the experiments.

\section{References}

[1] Nosaka, M., Oike. M., Kikuchi. M., Kamijo K. and Mayumi, T., "Tribo-Characteristics of SelfLubricating Ball Bearings for the LE-7 Liquid Hydrogen Rocket-Turbopunp," Tribology Transactions, 36, 3, 1993, 432-442.

[2] Franchek, N. M. and Childs, D. W., "Experimental Test Results for Four High-Speed, High-Pressure, Orifice- Compensated Hybrid Bearings," ASME Journal of Tribology, 116, 1, 1994, 147-153.

[3] Reddecliff, M. and Vohr, J. H., "Hydrostatic Bearings for Cryogenic Rocket Engine
Turbopumps," ASME Journal of Lubrication Technology, July 1969, 557-575.

[4] Bickel, M., Leuchs, M., Lange, H., Nelis, M. and Bozet, J. L., "Ceramic Journal Bearings in Cryogenic Turbo-pumps," Proc. 9 ${ }^{\text {th }}$ European Space Mechanisms \& Tribology Symposium, Liege, Sept. 2001, 1-10.

[5] Ohta, T. and Ogata, H., "Application of Hydrostatic Bearings to $\mathrm{LH}_{2}$ Turbopump," Proc. $4^{\text {th }}$ International Conference on Launcher Technology, Liege, December 2002, 1-6.

[6] Oike, M., Kikuchi, M., Takada, S., Sudo, T. and Yoshida, M., "Effect of the Recess Aspect Ratio on Cryogenic Hybrid Journal Bearings," Proc. World Tribology Conference Kyoto 2009, Kyoto, September 2009, 541.

[7] Oike, M., Kikuchi, M., Takada, S., Sudo, T. and Takano, T., "Robustness of Cryogenic Hybrid Journal Bearings," JAST Tribology Online, 7, 3, 2012, 171-178.

[8] Oike, M., Kikuchi, M., Takada, S., Sudo, T. and Takano, T., "Influences of Journal Rotating Direction on Cryogenic Hybrid Journal Bearings," JAST Tribology Online, 10, 2, 2015, 96-105.

[9] Oike, M., Nosaka, M., Kikuchi, M. and Hasegawa, S., "Two-Phase Flow in Floating-Ring Seals for Cryogenic Turbopumps," Tribology Transactions, 42, 2, 1999, 273-281.

[10] Brennen, C. E., "Cavitation and Bubble Dynamics," Oxford University Press, New York.

[11] Stepanoff, A. J., "Cavitation Properties of Liquids," Journal of Engineering Power, 80, 1964, 195-200.

[12] Vohr, J. H. and Chow, C. Y., "Characteristics of Herringbone-Grooved, Gas-Lubricated Journal Bearings," ASME Journal of Basic Engineering, 94, 1, 1965, 81-85. 